\title{
Meleagris Gallopavo Algorithm for Solving Optimal Reactive Power Problem
}

\author{
K. Lenin \\ Department of EEE, Prasad V. Potluri Siddhartha Institute of Technology, India
}

\begin{tabular}{l} 
Article Info \\
\hline Article history: \\
Received Jan 10, 2018 \\
Revised Feb 16, 2018 \\
Accepted Feb 28, 2018
\end{tabular}

\section{Keyword:}

Meleagris Gallopavo Algorithm Optimal reactive power

Poultry

Transmission loss

\begin{abstract}
In this paper, Meleagris Gallopavo Algorithm (MGA) is proposed for solving optimal reactive power problem. As a group-mate Meleagris gallopavo follow their poultry to explore food, at the same time it prevent the same ones to eat their own food. Always the overriding individuals have the lead to grab more food and Meleagris gallopavo would arbitrarily pinch the high-quality food which has been already found by other Meleagris gallopavo. In the region of the mother Meleagris gallopavo, Poults always search for food. In the projected MGA additional parameters are eliminated, in order to upsurge the search towards global optimization solution. Proposed MGA has been tested on two modes a. with the voltage stability Evaluation in standard IEEE 30 bus test system, b. Without voltage stability Evaluation in standard IEEE $30,57,118$ bus test systems \& practical 191 test system. Simulation results show clearly the better performance of the proposed MGA in reducing the real power loss, enhancement of static voltage stability Index and particularly voltage profiles within the specified limits.
\end{abstract}

Copyright $\left(C_{0} 2018\right.$ Institute of Advanced Engineering and Science. All rights reserved.

\section{Corresponding Author:}

K. Lenin,

Department of EEE,

Prasad V. Potluri Siddhartha Institute of Technology,

Kanuru, Vijayawada, Andhra Pradesh -520007, India.

Email: gklenin@gmail.com

\section{INTRODUCTION}

The main objective in optimal reactive power problem is to minimize the real power loss and to keep the voltage profile within the limits. Various mathematical techniques [1-8] have been utilized to solve the problem but have the complexity in managing inequality constraints. Start form genetic algorithm \& all Evolutionary algorithms [9-20] have been applied serially to solve the reactive power problem. But they also had their own advantages \& disadvantages in Exploration \& Exploitation. This paper proposes Meleagris Gallopavo Algorithm (MGA) to solve reactive power problem. In this projected algorithm both exploration $\&$ exploitation has been augmented equally in order to reach near to global optimum solution. As a groupmate Meleagris Gallopavo follow their poultry to explore food, at the same time it prevent the same ones to eat their own food. Always the overriding individuals have the lead to grab more food and Meleagris Gallopavo would arbitrarily pinch the high-quality food which has been already found by other Meleagris Gallopavo. In the region of the mother Meleagris Gallopavo, Poults always search for food. In the projected MGA additional parameters are eliminated, in order to upsurge the search towards global optimization solution. Proposed MGA has been tested on two modes a. with considering voltage stability Evaluation in standard IEEE 30 bus test system, b. Without considering voltage stability Evaluation in standard IEEE 30, 57, 118 bus test systems \& practical 191 test system. Simulation results show clearly the better performance 
of the proposed MGA in reducing the real power loss, enhancement of static voltage stability Index and particularly voltage profiles are within the specified limits.

\section{VOLTAGE STABILITY EVALUATION}

\subsection{Voltage stability evaluation by modal analysis}

For voltage stability enhancement in power systems Modal analysis methodology [25] has been used. The steady state system power flow equations are given by.

$$
\left[\begin{array}{l}
\Delta \mathrm{P} \\
\Delta \mathrm{Q}
\end{array}\right]=\left[\begin{array}{cc}
\mathrm{J}_{\mathrm{p} \theta} & \mathrm{J}_{\mathrm{pv}} \\
\mathrm{J}_{\mathrm{q} \theta} & \mathrm{J}_{\mathrm{QV}}
\end{array}\right]\left[\begin{array}{l}
\Delta \theta \\
\Delta V
\end{array}\right]
$$

Where

$\Delta \mathrm{P}=$ change in bus real power incrementally.

$\Delta \mathrm{Q}=$ change in bus reactive Power injection incrementally.

$\Delta \theta=$ change in bus voltage angle incrementally.

$\Delta \mathrm{V}=$ change in bus voltage Magnitude incrementally.

sub-matrixes of the System voltage stability are Jp $\theta$, JPV , JQ $\theta$, JQV jacobian matrix and it affected by both $\mathrm{P}$ and $\mathrm{Q}$.

Assume $\Delta \mathrm{P}=0$, to reduce equation (1) then,

$$
\begin{aligned}
& \Delta \mathrm{Q}=\left[\mathrm{J}_{\mathrm{QV}}-\mathrm{J}_{\mathrm{Q} \theta} \mathrm{J}_{\mathrm{P} \theta^{-1}} \mathrm{~J}_{\mathrm{PV}}\right] \Delta \mathrm{V}=\mathrm{J}_{\mathrm{R}} \Delta \mathrm{V} \\
& \Delta \mathrm{V}=\mathrm{J}^{-1}-\Delta \mathrm{Q}
\end{aligned}
$$

Where

$$
\mathrm{J}_{\mathrm{R}}=\left(\mathrm{J}_{\mathrm{QV}}-\mathrm{J}_{\mathrm{Q} \theta} \mathrm{J}_{\mathrm{P} \theta^{-1}} \mathrm{JPV}\right)
$$

$\mathrm{J}_{\mathrm{R}}$ is called the reduced Jacobian matrix of the system.

\subsection{Modes of voltage instability}

By computing the Eigen values and Eigen vectors voltage Stability characteristics of the system have been identified.

$$
\mathrm{J}_{\mathrm{R}}=\xi \wedge \eta
$$

Where,

$\xi=$ right eigenvector matrix of JR

$\eta=$ left eigenvector matrix of JR

$\Lambda=$ diagonal eigenvalue matrix of JR and

$$
\mathrm{J}_{\mathrm{R}^{-1}}=\xi \wedge^{-1} \eta
$$

From the equations (5) and (8), we can write,

$$
\Delta \mathrm{V}=\xi \wedge^{-1} \eta \Delta \mathrm{Q}
$$

Or

$$
\Delta \mathrm{V}=\sum_{\mathrm{I}} \frac{\xi_{\mathrm{i}} \eta_{\mathrm{i}}}{\lambda_{\mathrm{i}}} \Delta \mathrm{Q}
$$

Where $\xi_{i}$ is the ith column right eigenvector and $\eta$ the ith row left eigenvector of JR.

$\lambda \mathrm{i}$ is the ith Eigen value of JR.

The ith modal reactive power variation is given by,

$$
\Delta \mathrm{Q}_{\mathrm{mi}}=\mathrm{K}_{\mathrm{i}} \xi_{\mathrm{i}}
$$


where,

$$
\mathrm{K}_{\mathrm{i}}=\sum_{\mathrm{j}} \xi_{\mathrm{ij}^{2}}-1
$$

Where

$\xi \mathrm{ji}$ is the jth element of $\xi \mathrm{i}$

The corresponding ith modal voltage variation is mathematically given by,

$$
\Delta \mathrm{V}_{\mathrm{mi}}=\left[1 / \lambda_{\mathrm{i}}\right] \Delta \mathrm{Q}_{\mathrm{mi}}
$$

When $|\lambda \mathrm{i}|=0$ then the ith modal voltage will get collapsed.

In Equation (8), assume $\Delta \mathrm{Q}=\mathrm{ek}$ where ek has all its elements zero except the kth one being 1 . Then,

$$
\Delta \mathrm{V}=\sum_{\mathrm{i}} \frac{\eta_{1 \mathrm{k}} \xi_{1}}{\lambda_{1}}
$$

$\eta_{1 \mathrm{k}}$ k th element of $\eta_{1}$

$\mathrm{V}-\mathrm{Q}$ sensitivity at bus $\mathrm{k}$ is given by,

$$
\frac{\partial \mathrm{V}_{\mathrm{K}}}{\partial \mathrm{Q}_{\mathrm{K}}}=\sum_{\mathrm{i}} \frac{\mathrm{\eta}_{1 \mathrm{k}} \xi_{1}}{\lambda_{1}}=\sum_{\mathrm{i}} \frac{\mathrm{P}_{\mathrm{ki}}}{\lambda_{1}}
$$

\section{PROBLEM FORMULATION}

The key objectives of the reactive power dispatch problem is to minimize the system real power loss and also to maximize the static voltage stability margin (SVSM).

\subsection{Minimization of real power loss}

Real power loss (Ploss) Minimization in transmission lines is mathematically given as,

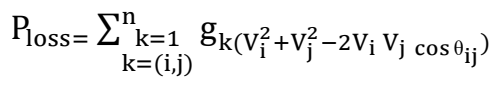

Where $\mathrm{n}$ is the number of transmission lines, $\mathrm{gk}$ is the conductance of branch $\mathrm{k}, \mathrm{Vi}$ and $\mathrm{Vj}$ are voltage magnitude at bus $\mathrm{i}$ and bus $\mathrm{j}$, and $\theta \mathrm{ij}$ is the voltage angle difference between bus $\mathrm{i}$ and bus $\mathrm{j}$.

\subsection{Minimization of voltage deviation}

At load buses minimization of the voltage deviation magnitudes (VD) is stated as follows,

$$
\text { Minimize } \mathrm{VD}=\sum_{\mathrm{k}=1}^{\mathrm{nl}}\left|\mathrm{V}_{\mathrm{k}}-1.0\right|
$$

Where $\mathrm{nl}$ is the number of load busses and $\mathrm{Vk}$ is the voltage magnitude at bus $\mathrm{k}$.

\subsection{System constraints}

These are the following constraints subjected to objective function as given below, Load flow equality constraints:

$$
\begin{aligned}
& P_{G i}-P_{D i}-V_{i \sum_{j=1}^{n b} V_{j}}\left[\begin{array}{cc}
G_{i j} & \cos \theta_{i j} \\
+B_{i j} & \sin \theta_{i j}
\end{array}\right]=0, i=1,2 \ldots, n b \\
& Q_{G i}-Q_{D i}-V_{i \sum_{j=1}^{n b} V_{j}}\left[\begin{array}{cc}
G_{i j} & \sin \theta_{i j} \\
+B_{i j} & \cos \theta_{i j}
\end{array}\right]=0, i=1,2 \ldots, n b
\end{aligned}
$$

Where, $\mathrm{nb}$ is the number of buses, $\mathrm{PG}$ and QG are the real and reactive power of the generator, PD and QD are the real and reactive load of the generator, and $\mathrm{Gij}$ and $\mathrm{Bij}$ are the mutual conductance and susceptance between bus $\mathrm{i}$ and bus $\mathrm{j}$.

Generator bus voltage $\left(\mathrm{V}_{\mathrm{Gi}}\right)$ inequality constraint:

$$
\mathrm{V}_{\mathrm{Gi}}^{\min } \leq \mathrm{V}_{\mathrm{Gi}} \leq \mathrm{V}_{\mathrm{Gi}}^{\max }, \mathrm{i} \in \mathrm{ng}
$$


Load bus voltage $\left(\mathrm{V}_{\mathrm{Li}}\right)$ inequality constraint:

$$
\mathrm{V}_{\mathrm{Li}}^{\min } \leq \mathrm{V}_{\mathrm{Li}} \leq \mathrm{V}_{\mathrm{Li}}^{\max }, \mathrm{i} \in \mathrm{nl}
$$

Switchable reactive power compensations $\left(\mathrm{Q}_{\mathrm{Ci}}\right)$ inequality constraint:

$$
\mathrm{Q}_{\mathrm{Ci}}^{\min } \leq \mathrm{Q}_{\mathrm{Ci}} \leq \mathrm{Q}_{\mathrm{Ci}}^{\max }, \mathrm{i} \in \mathrm{nc}
$$

Reactive power generation $\left(\mathrm{Q}_{\mathrm{Gi}}\right)$ inequality constraint:

$$
\mathrm{Q}_{\mathrm{Gi}}^{\min } \leq \mathrm{Q}_{\mathrm{Gi}} \leq \mathrm{Q}_{\mathrm{Gi}}^{\max }, \mathrm{i} \in \mathrm{ng}
$$

Transformers tap setting $\left(\mathrm{T}_{\mathrm{i}}\right)$ inequality constraint:

$$
\mathrm{T}_{\mathrm{i}}^{\min } \leq \mathrm{T}_{\mathrm{i}} \leq \mathrm{T}_{\mathrm{i}}^{\max }, \mathrm{i} \in \mathrm{nt}
$$

Transmission line flow $\left(\mathrm{S}_{\mathrm{Li}}\right)$ inequality constraint:

$$
\mathrm{S}_{\mathrm{Li}}^{\min } \leq \mathrm{S}_{\mathrm{Li}}^{\max }, \mathrm{i} \in \mathrm{nl}
$$

Where, nc, ng and nt are numbers of the switchable reactive power sources, generators and transformers.

\section{MELEAGRIS GALLOPAVO ALGORITHM (MGA)}

MGA is based on the Meleagris Gallopavo behaviour. It consists of several groups and each group encompass a leading male Meleagris Gallopavo, couple of Meleagris Gallopavo, and Poults. Depend on the fitness values of the Meleagris Gallopavo they divide themselves into several groups and identity of the Meleagris Gallopavo (leading male Meleagris Gallopavo, couple of Meleagris Gallopavo, and Poults) has been determined. Based upon the best fitness values Meleagris Gallopavo would be acted as poultry, \& also as head poultry in a group. And which has worst fitness values would be designated as Poults. Remaining all would be the common Meleagris Gallopavo and it arbitrarily chooses which group to live in. Mother-child relationship between the Female Meleagris Gallopavo and the Poults is also arbitrarily established as shown in Figure 1, 2, 3.

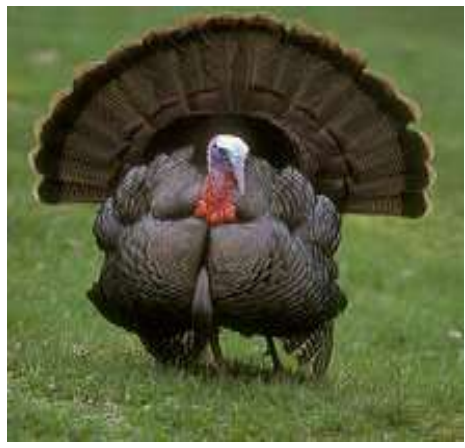

Figure 1. Meleagris gallopavo

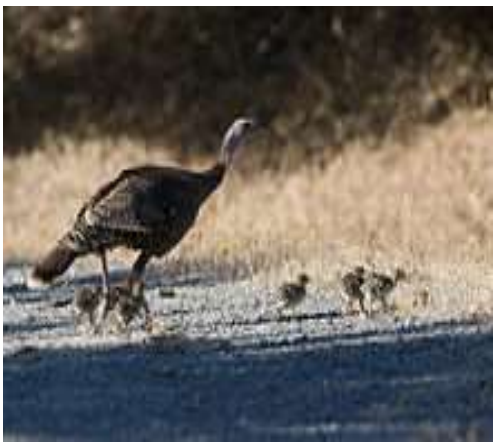

Figure 2. Female meleagris gallopavo with poults

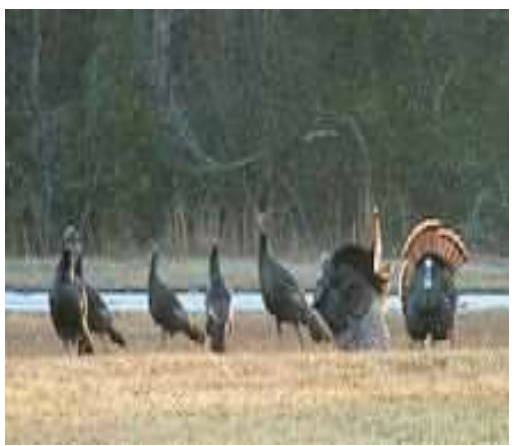

Figure 3. Meleagris gallopavo in group

Supremacy relationship and mother-child relationship in a group will remain unchanged \& only update every several $(G)$ time steps. In the as a group-mate Meleagris Gallopavo follow their poultry (leading male Meleagris Gallopavo) to explore food, at the same time it prevent the same ones to eat their own food. Always the overriding individuals have the lead to grab more food and Meleagris Gallopavo would arbitrarily pinch the high-quality food which has been already found by other Meleagris Gallopavo. In the region of the mother Meleagris Gallopavo Poults always search for food. In the projected MGA additional parameters are eliminated, in order to upsurge the search towards global optimization solution. 
Always advantages for the dominant individuals in grab the food. Better fitness poultry will have high priority for food access when compared with worse fitness values poultry. It has been simulated that the poultry with better fitness values can explore for food in a wider range of places than that of the with poultry worse fitness values. This can be articulated mathematically as follows.

$$
\begin{aligned}
& y_{i, j}^{t+1}=y_{i, j}^{t} *\left(1+\operatorname{Rand}\left(0, \sigma^{2}\right)\right) \\
& \sigma^{2}=\left\{\begin{array}{c}
1 \quad f_{i} \leq f_{k} \\
\exp \left(\frac{f_{k}-f_{i}}{\left|f_{i}+\varepsilon\right|}\right) \text { other wise }
\end{array} k \in[1, N], k \neq 1\right.
\end{aligned}
$$

Where $\operatorname{Rand}\left(0, \sigma^{2}\right)$ is a Gaussian distribution [21] with mean 0 and standard deviation $\sigma^{2}, \varepsilon$,which is used to shun the zero-division-error $\&$ the smallest constant. $k$, a poultry index, is arbitrarily selected from the poultry group, $\mathrm{f}$ is the fitness value of the corresponding $\mathrm{y}$. Hens, follow their group-mate poultry to explore for food. Furthermore, they would also arbitrarily steal the good food found by other Meleagris Gallopavo. Dominant Meleagris Gallopavo would have high advantage in competing for food than the more passive ones. This phenomenon can be formulated mathematically as follows,

$$
\begin{aligned}
& y_{i, j}^{t+1}=y_{i, j}^{t}+S 1 * \text { Rand } *\left(y_{r^{1}, j}^{t}-y_{i, j}^{t}\right)+S 2 * \text { Rand } *\left(y_{r^{2}, j}^{t}-y_{i, j}^{t}\right) \\
& S 1=\exp \left(\frac{f_{i}-f_{r^{1}}}{\operatorname{abs}\left(f_{i}\right)+\varepsilon}\right) \\
& S 2=\exp \left(f_{r^{2}}-f_{i}\right)
\end{aligned}
$$

Where Rand is a uniform random number over $r^{1} \in[0,1]$, is an index of the poultry, which is the ith Meleagris Gallopavo's group-mate, while $r^{2} \in[0,1]$, is an index of the Meleagris Gallopavo, which is arbitrarily chosen from the swarm $r^{1} \neq r^{2}$.

Around the mother Meleagris Gallopavo, Poults move to forage for food. This is formulated by,

$$
y_{i, j}^{t+1}=y_{i, j}^{t}+F L *\left(y_{m, j}^{t}-y_{i, j}^{t}\right)
$$

Where $y_{m, j}^{t}$, stands for the position of the i-th Poults's mother $m \in[1, N]$. FL[FL $\left.\in(0,2)\right]$ is a parameter, \& it indicates that the Poults would follow its mother to forage for food. Consider the individual differences, the FL of each Poult would arbitrarily choose between 0 and 2

Meleagris Gallopavo group has wide range of exploration \& it lead to have global search ability Number of parameters is reduced but the exploration and exploitation of exploration space can be done by all individual of population. The multi steps are separated be two steps. The first step is diversification (Exploration) in which Meleagris Gallopavo group's first step is reduced due to the largest area search ability; this reduced form is used to exploring the global optima. Each individual of Meleagris Gallopavo population move to the other position by the best Meleagris Gallopavo and the other Meleagris Gallopavo. The second one is intensification (exploitation) \& it evaluates the value from the first step. Since the poultry and Poults group have the local exploration ability, the both group will be utilized to exploit the existing position from the first step. Alike to the first step, each individual of Meleagris Gallopavo population is considered as poultry then as a single Meleagris Gallopavo.

Initialization of Population

Meleagris Gallopavo swarm population are initialized by,

$$
y_{i, j}=l b+\operatorname{Rand}(u b-l b)
$$

With $l b$ and $u b$ are lower bound and upper bound of the exploration space.

Exploration Step

This phase reduces the Meleagris Gallopavo numerous step \& used to explore the global optimum by eliminating the Meleagris Gallopavo group parameter. Against two individual of the population each individual of Meleagris Gallopavo population revamp their position and it formulated as,

$$
y_{i, j}(*)=y_{i, j}+S 1 * \operatorname{Rand} *\left(y_{l . j}-y_{i, j}\right)+S 2 * \operatorname{Rand} *\left(y_{n, j}-y_{i, j}\right)
$$


With,

$$
\begin{aligned}
& S 1=\exp \left(\frac{\left(f_{i}-f_{l}\right)}{\left|f_{i}+\varepsilon\right|}\right) \\
& S 2=\exp \left(f_{n}-f_{i}\right)
\end{aligned}
$$

$y_{l}, y_{n} \in[1, N]$ is arbitrarily chosen form Meleagris Gallopavo swarm with $y_{i} \neq y_{l} \neq y_{n}$.

After $y_{i, j}(*)$ obtained, the objective value (fitness value) compared with the fitness value of $y_{i, j}$. The solution that has the most excellent fitness value is chosen as an individual of new population \& it called as individual of the global population $\left(y_{i, j}(g)\right)$.

\section{Exploitation Step}

Through exploration step candidate solution (Meleagris Gallopavo individual) will be obtained \& it will be revamped again by exploiting the neighbourhood using the process of reducing poultry and Meleagris Gallopavo formula. Alike with exploration step, this step will also eliminate poultry and Meleagris Gallopavo groups. Local optimum search carried out in two steps, the first step is by using the reduction poultry formula as follows.

$$
\begin{aligned}
& y_{i, j}(* *)=y_{i, j}(g) *\left(1+\operatorname{Rand}\left(0, \sigma^{2}\right)\right) \\
& \sigma^{2}=\left\{\begin{array}{c}
1 \quad f_{i}(g) \leq f_{l}(g) \\
\exp \left(\frac{f_{l}(g)-f_{i}(g)}{\left|f_{i}(g)+\varepsilon\right|}\right) \text { other wise }
\end{array} l \in[1, N](g), l \neq i\right.
\end{aligned}
$$

The first local optimum solution obtained by exploiting the global optimum population by using the Equation (27). After that the next step is comparing its fitness value with fitness value of previous global optimum solution. The solution which has most excellent fitness value is chosen as individual of the first renewal population that called Local population I $\left(y_{i, j}\left(l_{1}\right)\right)$.

After new-fangled local population I $\left(y_{i, j}\left(l_{1}\right)\right)$ obtained, subsequently the final step of MGA is to find the more local optimum (the second local optimum) by using the reduced Meleagris Gallopavo formula as follows:

$$
y_{i, j}(* * *)=y_{i, j}\left(l_{1}\right)+C *\left(y_{n, j}\left(l_{1}\right)-y_{i, j}\left(l_{1}\right)\right)
$$

$y_{n} \in[1, N]$ is arbitrarily chosen from the local population I with $y_{i} \neq y_{n}$ and $C(C \in(0,2))$.

After the second local optimum obtained, the next step is compares its fitness value with the previous local optimum solution fitness value. The solution which has most excellent fitness value is chosen as individual of the second renewal population that called local population $\operatorname{II}\left(y_{i, j}\left(l_{2}\right)\right)$. This population is used as the preliminary population for the subsequent iteration until the stopping criteria are met.

\section{MGA for solving reactive power problem}

a. By using equation (30) Initialize a population of N Meleagris Gallopavo

b. N Meleagris Gallopavo fitness value has been evaluated; $t=0$

c. While $t<G$

d. For $i=1 ; N$

aa. By Equation (31) explore the global optimum \& Selection of individual global population $\left(y_{i, j}(g)\right)$ has to be done.

bb. Exploitation of the local optimum

aaa. By using equation (34) first local optimum has been found \& Selection of individual local population I $\left(y_{i, j}\left(l_{1}\right)\right)$ have to be done.

bbb. By using (36) the second local optimum has to be found \& Selection of individual local population II $\left(y_{i, j}\left(l_{2}\right)\right)$ have to be done. 
e. End For

End While

\section{SIMULATION RESULTS}

\subsection{With considering voltage stability evaluation}

At first the efficiency of the proposed MGA has been tested it in standard IEEE-30 bus system with voltage stability evaluation.

Standard IEEE-30 bus system has 6 generator buses, 24 load buses and 41 transmission lines of which four branches are (6-9), (6-10), (4-12) and (28-27)-are with the tap setting transformers. The lower voltage magnitude limits at all buses are 0.95 p.u. and the upper limits are 1.1 for all the PV buses and 1.05 p.u. for all the PQ buses and the reference bus. In Table 1 optimal values of control variables along with the minimum loss obtained are given $\&$ it was found that there are no limit violations in any of the state variables corresponding to this control variables.

Table 2 indicates the optimal values of the control variables \& there is no limit violations in state variables. Mainly static voltage stability margin (SVSM) has increased from 0.2478 to 0.2489 . contingency analysis was conducted using the control variable setting obtained in case 1 and case 2 to determine the voltage security of the system. In Table 3 the Eigen values equivalents to the four critical contingencies are given. Result reveal about the Eigen value has been improved considerably for all contingencies in the second case. Table 5 shows MGA reduces real power losses considerably when compared to other standard reported algorithms.

Table 1. Results of MGA-optimal Reactive Power Control Variables

\begin{tabular}{cc}
\hline Control Variables & Values of Variable Setting \\
V1 & 1.0400 \\
V2 & 1.0410 \\
V5 & 1.0400 \\
V8 & 1.0310 \\
V11 & 1.0010 \\
V13 & 1.0320 \\
T11 & 1.0000 \\
T12 & 1.0000 \\
T15 & 1.0100 \\
T36 & 1.0100 \\
Qc10 & 2 \\
Qc12 & 2 \\
Qc15 & 3 \\
Qc17 & 0 \\
Qc20 & 2 \\
Qc23 & 3 \\
Qc24 & 3 \\
Qc29 & 2 \\
Real power loss & 4.2956 \\
SVSM & 0.2478 \\
\hline
\end{tabular}

Table 2. Results of MGA-optimal Control Variables of Voltage Stability Control Reactive Power Dispatch

\begin{tabular}{cc}
\hline Control Variables & Values of Variable Setting \\
V1 & 1.0440 \\
V2 & 1.0430 \\
V5 & 1.0420 \\
V8 & 1.0360 \\
V11 & 1.0030 \\
V13 & 1.0300 \\
T11 & 0.0900 \\
T12 & 0.0900 \\
T15 & 0.0900 \\
T36 & 0.0900 \\
Qc10 & 3 \\
Qc12 & 3 \\
Qc15 & 2 \\
Qc17 & 3 \\
Qc20 & 0 \\
Qc23 & 2 \\
Qc24 & 2 \\
Qc29 & 3 \\
Real power loss & 4.9878 \\
SVSM & 0.2489 \\
\hline
\end{tabular}

Table 3. Voltage Stability Under Contingency State

\begin{tabular}{cccc}
\hline Sl.No & Contingency & $\begin{array}{c}\text { Optimal Reactive Power } \\
\text { Dispatch Setting }\end{array}$ & $\begin{array}{c}\text { Voltage Stability Control Reactive } \\
\text { Power Dispatch Setting }\end{array}$ \\
\hline 1 & $28-27$ & 0.1452 & 0.1424 \\
2 & $4-12$ & 0.1649 & 0.1651 \\
3 & $1-3$ & 0.1761 & 0.1772 \\
4 & $2-4$ & 0.2024 & 0.2041 \\
\hline
\end{tabular}


Table 4. Limit Violation Checking of State Variables

\begin{tabular}{|c|c|c|c|c|}
\hline \multirow{2}{*}{ State variables } & \multicolumn{2}{|c|}{ limits } & \multirow{2}{*}{$\begin{array}{c}\text { Optimal Reactive } \\
\text { PowerDispatch Setting }\end{array}$} & \multirow{2}{*}{$\begin{array}{c}\text { Voltage Stability Control Reactive } \\
\text { Power Dispatch Setting }\end{array}$} \\
\hline & Lower & upper & & \\
\hline Q1 & -20 & 152 & 1.3422 & -1.3269 \\
\hline Q2 & -20 & 61 & 8.9900 & 9.8232 \\
\hline Q5 & -15 & 49.92 & 25.920 & 26.001 \\
\hline Q8 & -10 & 63.52 & 38.8200 & 40.802 \\
\hline Q11 & -15 & 42 & 2.9300 & 5.002 \\
\hline Q13 & -15 & 48 & 8.1025 & 6.033 \\
\hline $\mathrm{V} 3$ & 0.95 & 1.05 & 1.0372 & 1.0392 \\
\hline V4 & 0.95 & 1.05 & 1.0307 & 1.0328 \\
\hline V6 & 0.95 & 1.05 & 1.0282 & 1.0298 \\
\hline V7 & 0.95 & 1.05 & 1.0101 & 1.0152 \\
\hline V9 & 0.95 & 1.05 & 1.0462 & 1.0412 \\
\hline V10 & 0.95 & 1.05 & 1.0482 & 1.0498 \\
\hline V12 & 0.95 & 1.05 & 1.0400 & 1.0466 \\
\hline V14 & 0.95 & 1.05 & 1.0474 & 1.0443 \\
\hline V15 & 0.95 & 1.05 & 1.0457 & 1.0413 \\
\hline V16 & 0.95 & 1.05 & 1.0426 & 1.0405 \\
\hline V17 & 0.95 & 1.05 & 1.0382 & 1.0396 \\
\hline V18 & 0.95 & 1.05 & 1.0392 & 1.0400 \\
\hline V19 & 0.95 & 1.05 & 1.0381 & 1.0394 \\
\hline V20 & 0.95 & 1.05 & 1.0112 & 1.0194 \\
\hline V21 & 0.95 & 1.05 & 1.0435 & 1.0243 \\
\hline V22 & 0.95 & 1.05 & 1.0448 & 1.0396 \\
\hline V23 & 0.95 & 1.05 & 1.0472 & 1.0372 \\
\hline V24 & 0.95 & 1.05 & 1.0484 & 1.0372 \\
\hline V25 & 0.95 & 1.05 & 1.0142 & 1.0192 \\
\hline V26 & 0.95 & 1.05 & 1.0494 & 1.0422 \\
\hline V27 & 0.95 & 1.05 & 1.0472 & 1.0452 \\
\hline V28 & 0.95 & 1.05 & 1.0243 & 1.0283 \\
\hline V29 & 0.95 & 1.05 & 1.0439 & 1.0419 \\
\hline V30 & 0.95 & 1.05 & 1.0418 & 1.0397 \\
\hline
\end{tabular}

Table 5. Comparison of Real Power Loss

\begin{tabular}{cc}
\hline Methods & Minimum loss (MW) \\
\hline Evolutionary programming [22] & 5.0159 \\
Genetic algorithm [23] & 4.665 \\
Real coded GA with Lindex as SVSM [24] & 4.568 \\
Real coded genetic algorithm [25] & 4.5015 \\
Proposed MGA method & 4.2956 \\
\hline
\end{tabular}

\subsection{Without considering voltage stability evaluation}

Validity of the proposed MGA has been verified by testing in standard IEEE 30-bus without considering Voltage stability evaluation.

Standard IEEE 30-bus has 41 branches, 6 generator-bus, 4 transformer-tap settings, with 2 shunt reactive compensators buses. 2, 5, 8, 11 and 13 are considered as PV generator buses \& Bus 1 is taken as slack bus, others are PQ load buses. In Table 6 Control variables limits are given.

In Table 7 gives the power limits of generators buses. Table 8 shows the values of control variables. Table 9 narrates the performance of the proposed algorithm. Overall comparison of the results of optimal solution obtained by various methods is given in Table 10 .

Table 6. Primary Variable Limits (PU)

\begin{tabular}{cllc}
\hline Variables & Min. & Max. & Category \\
Generator bus & 0.95 & 1.1 & continuous \\
Load bus & 0.95 & 1.05 & continuous \\
Transformer-tap & 0.9 & 1.1 & discrete \\
Shunt reactive compensator & -0.11 & 0.31 & discrete
\end{tabular}

Table 7. Generators Power Limits

\begin{tabular}{cccccc}
\hline Bus & Pg & Pgmin & Pgmax & Qgmin & Qmax \\
1 & 96.00 & 49 & 200 & 0 & 10 \\
2 & 79.00 & 18 & 79 & -40 & 50 \\
5 & 49.00 & 14 & 49 & -40 & 40 \\
8 & 21.00 & 11 & 31 & -10 & 40 \\
11 & 21.00 & 11 & 28 & -6 & 24 \\
13 & 21.00 & 11 & 39 & -6 & 24 \\
\hline
\end{tabular}


Table 8. After Optimization Values of Control Variables

\begin{tabular}{cc}
\hline Control Variables & MGA \\
\hline V1 & 1.0413 \\
V2 & 1.0419 \\
V5 & 1.0189 \\
V8 & 1.0276 \\
V11 & 1.0684 \\
V13 & 1.0487 \\
T4,12 & 0.00 \\
T6,9 & 0.01 \\
T6,10 & 0.90 \\
T28,27 & 0.91 \\
Q10 & 0.10 \\
Q24 & 0.10 \\
Real power loss & 4.2702 \\
Voltage deviation & 0.9072 \\
\hline
\end{tabular}

Table 9. Performance of MGA

$\begin{array}{cc}\text { Iterations } & 25 \\ \text { Time taken (secs) } & 9.72 \\ \text { Real power loss } & 4.2702\end{array}$

Table 10. Comparison of Results

\begin{tabular}{lc} 
Techniques & Real power loss (MW) \\
\hline Wu et al., 1998) [26] & 4.98 \\
hao et al., 2005) [27] & 4.9262 \\
devan et al., 2010) [28] & 5.988 \\
devan et al., 2010) [28] & 4.963 \\
adevan et al., 2010) [28] & 4.980 \\
adevan et al., 2010) [28] & 4.926 \\
hadevan et al., 2010) [28] & 4.7208 \\
azali et al., 2011) [29] & 4.7624 \\
kthivel et al., 2013) [30] & 4.690 \\
roporma et al.,2016) [31] & 4.87231 \\
\hline
\end{tabular}

Then MGA has been tested in standard IEEE-57 bus power system. 18, 25 and 53 are reactive power compensation buses. PV buses are 2, 3, 6, 8, 9 and 12 and slack-bus is bus 1 . In Table 11 system variable limits are given.

IEEE-57 preliminary conditions for the bus power system are given as follows:

$\mathrm{P}_{\text {load=12 }} 12.110$ p.u. $\mathrm{Q}_{\mathrm{load}}=3.050$ p.u.

Complete sum of initial generations and power losses are attained as follows:

$\sum P_{G}=12.429$ p.u. $\sum Q_{G}=3.3137$ p.u.

$\mathrm{P}_{\text {loss }}=0.25851$ p.u. $\mathrm{Q}_{\text {loss }}=-1.2059$ p.u.

Control variables values obtained after optimization is given in Table 12. Comparisons of results are shown in Table 13.

Table 11. Variable Limits

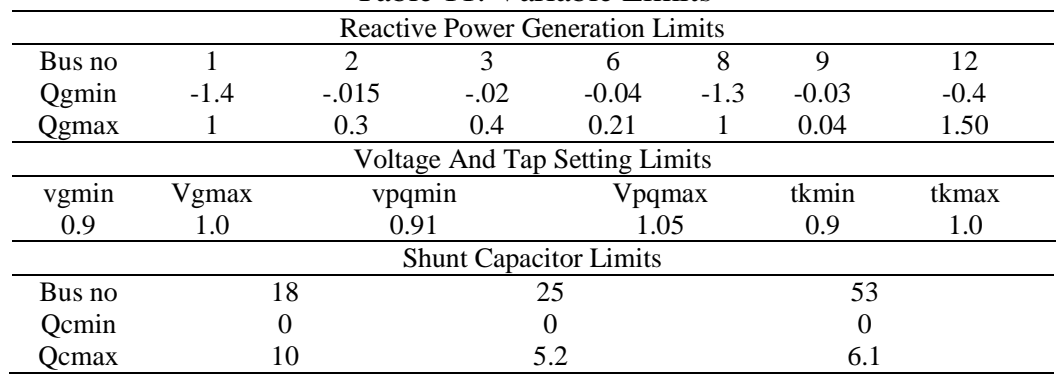


Table 12. Control Variables Obtained After Optimization

\begin{tabular}{cc}
\hline Control Variables & MGA \\
\hline V1 & 1.10 \\
V2 & 1.0321 \\
V6 & 1.0314 \\
V8 & 1.0218 \\
V9 & 1.0214 \\
V12 & 1.0010 \\
Qc18 & 1.0100 \\
Qc25 & 0.0660 \\
Qc53 & 0.2000 \\
T4-18 & 0.0472 \\
T21-20 & 1.0011 \\
T24-25 & 1.0424 \\
T24-26 & 0.8600 \\
T7-29 & 0.8701 \\
T34-32 & 1.0500 \\
T11-41 & 0.8710 \\
T15-45 & 1.0101 \\
T14-46 & 1.0301 \\
T10-51 & 0.9100 \\
T13-49 & 1.0200 \\
T11-43 & 1.0601 \\
T40-56 & 0.9100 \\
T39-57 & 0.9001 \\
T9-55 & 0.9501 \\
& 0.9500 \\
\hline
\end{tabular}

Table 13. Comparison Results

\begin{tabular}{ccccc}
\hline No. & $\begin{array}{c}\text { Optimization } \\
\text { Algorithm }\end{array}$ & $\begin{array}{c}\text { Finest } \\
\text { Solution }\end{array}$ & Poorest Solution & $\begin{array}{c}\text { Normal } \\
\text { Solution }\end{array}$ \\
\hline 1 & NLP [32] & 0.25902 & 0.30854 & 0.27858 \\
2 & CGA [32] & 0.25244 & 0.27507 & 0.26293 \\
3 & AGA [32] & 0.24564 & 0.26671 & 0.25127 \\
4 & PSO-w [32] & 0.24270 & 0.26152 & 0.24725 \\
5 & PSO-cf [32] & 0.24280 & 0.26032 & 0.24698 \\
6 & CLPSO [32] & 0.24515 & 0.24780 & 0.24673 \\
7 & SPSO-07 [32] & 0.24430 & 0.25457 & 0.24752 \\
8 & L-DE [32] & 0.27812 & 0.41909 & 0.33177 \\
9 & L-SACP-DE [32] & 0.27915 & 0.36978 & 0.31032 \\
10 & L-SaDE [32] & 0.24267 & 0.24391 & 0.24311 \\
11 & SOA [32] & 0.24265 & 0.24280 & 0.24270 \\
12 & LM [33] & 0.2484 & 0.2922 & 0.2641 \\
13 & MBEP1 [33] & 0.2474 & 0.2848 & 0.2643 \\
14 & MBEP2 [33] & 0.2482 & 0.283 & 0.2592 \\
15 & BES100 [33] & 0.2438 & 0.263 & 0.2541 \\
16 & BES200 [33] & 0.3417 & 0.2486 & 0.2443 \\
17 & Proposed MGA & 0.22092 & 0.23034 & 0.22218 \\
\hline
\end{tabular}

Then MGA has been tested in standard IEEE 118-bus test system [34].The system has 54 generator buses, 64 load buses, 186 branches and 9 of them are with the tap setting transformers. The limits of voltage on generator buses are 0.95-1.1 per-unit., and on load buses are $0.95-1.05$ per-unit. The limit of transformer rate is $0.9-1.1$, with the changes step of 0.025 . In Table 14 the limitations of reactive power source are listed, with the change in step of 0.01 .

Comparison results are shown in Table 15 and the results clearly show the better performance of proposed MGA in reducing the real power loss.

\begin{tabular}{cccccccc}
\hline \multicolumn{1}{c}{ Table 14. Limitation of Reactive Power Sources } \\
\hline BUS & 5 & 34 & 37 & 44 & 45 & 46 & 48 \\
QCMAX & 0 & 14 & 0 & 10 & 10 & 10 & 15 \\
QCMIN & -40 & 0 & -25 & 0 & 0 & 0 & 0 \\
BUS & 74 & 79 & 82 & 83 & 105 & 107 & 110 \\
QCMAX & 12 & 20 & 20 & 10 & 20 & 6 & 6 \\
QCMIN & 0 & 0 & 0 & 0 & 0 & 0 & 0 \\
\hline
\end{tabular}

\begin{tabular}{ccccc}
\hline \multicolumn{5}{c}{ Table 15. Comparison Results } \\
\hline $\begin{array}{c}\text { Active power } \\
\text { loss (MW) }\end{array}$ & $\begin{array}{c}\text { BBO } \\
{[35]}\end{array}$ & $\begin{array}{c}\text { ILSBBO/ } \\
\text { strategy1 } \\
{[35]}\end{array}$ & $\begin{array}{c}\text { ILSBBO/ } \\
\text { strategy1 } \\
{[35]}\end{array}$ & $\begin{array}{c}\text { Proposed } \\
\text { MGA }\end{array}$ \\
\hline Min & 128.77 & 126.98 & 124.78 & 118.02 \\
Max & 132.64 & 137.34 & 132.39 & 121.64 \\
Average & 130.21 & 130.37 & 129.22 & 119.28 \\
\hline
\end{tabular}


Then the MGA has been tested in practical 191 test system and the following results have been obtained. In Practical 191 test bus system-Number of Generators=20, Number of lines=200, Number of buses $=191$ Number of transmission lines=55. Table 16 shows the optimal control values of practical 191 test system obtained by MGA. And Table 17 shows the results about the value of the real power loss by obtained by Meleagris Gallopavo Algorithm (MGA).

\begin{tabular}{|c|c|c|c|c|c|c|}
\hline \multicolumn{2}{|c|}{ VG1 } & \multicolumn{2}{|l|}{1.1000} & \multicolumn{2}{|l|}{ VG 11} & 0.9000 \\
\hline & & 0.7800 & & VG 12 & & 1.0000 \\
\hline & & 1.0100 & & VG 13 & & 1.0000 \\
\hline & & 1.0100 & & VG 14 & & 0.9000 \\
\hline & & 1.1000 & & VG 15 & & 1.0000 \\
\hline & & 1.1000 & & VG 16 & & 1.0000 \\
\hline & & 1.1000 & & VG 17 & & 0.9000 \\
\hline & & 1.0100 & & VG 18 & & 1.0000 \\
\hline & & 1.1000 & & VG 19 & & 1.1000 \\
\hline & & 1.0100 & & VG 20 & & 1.1000 \\
\hline $\mathrm{T} 1$ & 1.0000 & $\mathrm{~T} 21$ & 0.9000 & & T41 & 0.9000 \\
\hline $\mathrm{T} 2$ & 1.0000 & $\mathrm{~T} 22$ & 0.9000 & & $\mathrm{~T} 42$ & 0.9000 \\
\hline $\mathrm{T} 3$ & 1.0000 & $\mathrm{~T} 23$ & 0.9000 & & $\mathrm{~T} 43$ & 0.9100 \\
\hline $\mathrm{T} 4$ & 1.1000 & $\mathrm{~T} 24$ & 0.9000 & & $\mathrm{~T} 44$ & 0.9100 \\
\hline $\mathrm{T} 5$ & 1.0000 & $\mathrm{~T} 25$ & 0.9000 & & $\mathrm{~T} 45$ & 0.9100 \\
\hline T6 & 1.0000 & $\mathrm{~T} 26$ & 1.0000 & & $\mathrm{~T} 46$ & 0.9000 \\
\hline $\mathrm{T} 7$ & 1.0000 & $\mathrm{~T} 27$ & 0.9000 & & $\mathrm{~T} 47$ & 0.9100 \\
\hline $\mathrm{T} 8$ & 1.0100 & $\mathrm{~T} 28$ & 0.9000 & & $\mathrm{~T} 48$ & 1.0000 \\
\hline T9 & 1.0000 & $\mathrm{~T} 29$ & 1.0100 & & T49 & 0.9000 \\
\hline $\mathrm{T} 10$ & 1.0000 & $\mathrm{~T} 30$ & 0.9000 & & T50 & 0.9000 \\
\hline $\mathrm{T} 11$ & 0.9000 & $\mathrm{~T} 31$ & 0.9000 & & T51 & 0.9000 \\
\hline $\mathrm{T} 12$ & 1.0000 & $\mathrm{~T} 32$ & 0.9000 & & T52 & 0.9000 \\
\hline $\mathrm{T} 13$ & 1.0100 & $\mathrm{~T} 33$ & 1.0100 & & T53 & 1.0000 \\
\hline $\mathrm{T} 14$ & 1.0100 & $\mathrm{~T} 34$ & 0.9000 & & T54 & 0.9000 \\
\hline $\mathrm{T} 15$ & 1.0100 & $\mathrm{~T} 35$ & 0.9000 & & T55 & 0.9000 \\
\hline
\end{tabular}

Table 17. Optimum Real Power Loss Values Obtained for Practical 191 Utility (Indian) System by MGA

\begin{tabular}{cc}
\hline Real power Loss (MW) & MGA \\
\hline Min & 145.4180 \\
Max & 147.6780 \\
Average & 146.1020 \\
\hline
\end{tabular}

\section{CONCLUSION}

MGA has been successfully solved reactive power problem. In the projected MGA additional parameters are eliminated, in order to upsurge the search towards global optimization solution. Proposed MGA has been tested on two modes a. with the voltage stability Evaluation in standard IEEE 30 bus test system, b. Without voltage stability Evaluation in standard IEEE 30, 57,118 bus test systems \& practical 191 test system. Simulation results show clearly the better performance of the proposed MGA in reducing the real power loss, enhancement of static voltage stability Index and particularly voltage profiles within the specified limits.

\section{REFERENCES}

[1] O. Alsac and B. Stott, "Optimal Load Flow with Steady-State Security," in IEEE Transactions on Power Apparatus and Systems, vol. PAS-93, no. 3, pp. 745-751, May 1974.

[2] K. Y. Lee, Y. M. Park and J. L. Ortiz, "A United Approach to Optimal Real and Reactive Power Dispatch," in IEEE Transactions on Power Apparatus and Systems, vol. PAS-104, no. 5, pp. 1147-1153, May 1985.

[3] A. Monticelli, M. V. F. Pereira and S. Granville, "Security-Constrained Optimal Power Flow with PostContingency Corrective Rescheduling," in IEEE Transactions on Power Systems, vol. 2, no. 1, pp. 175-180, Feb. 1987.

[4] N. Deeb and S. M. Shahidehpour, "Linear reactive power optimization in a large power network using the decomposition approach," in IEEE Transactions on Power Systems, vol. 5, no. 2, pp. 428-438, May 1990.

[5] E. Hcbson, "Network Constrained Reactive Power Control Using Linear Programming," in IEEE Transactions on Power Apparatus and Systems, vol. PAS-99, no. 3, pp. 868-877, May 1980.

[6] K. Y. Lee, Y. M. Park and J. L. Ortiz, "Fuel-cost minimisation for both real-and reactive-power dispatches," in IEE Proceedings C - Generation, Transmission and Distribution, vol. 131, no. 3, pp. 85-93, May 1984

[7] M. K. Mangoli, K. Y. Lee, "Optimal real and reactive power control using linear programming," Electric Power Systems Research, vol. 26, No. 1, pp. 1-10, January 1993. 
[8] C. A. Canizares, A. C. Z. De Souza and V. H. Quintana, "Comparison of performance indices for detection of proximity to voltage collapse," in IEEE Transactions on Power Systems, vol. 11, no. 3, pp. 1441-1450, Aug. 1996.

[9] K. Anburaja, "Optimal power flow using refined genetic algorithm," Electric Power Components and System, vol. 30, no. 10, pp. 1055-1063, 2002.

[10] D. Devaraj and B. Yegnanarayana, "Genetic-algorithm-based optimal power flow for security enhancement," in IEE Proceedings - Generation, Transmission and Distribution, vol. 152, no. 6, pp. 899-905, 4 Nov. 2005.

[11] A. Berizzi, C. Bovo, M. Merlo, M. Delfanti, "A ga approach to compare orpf objective functions including secondary voltage regulation," Electric Power Systems Research, vol. 84, no. 1, pp. 187-194, 2012.

[12] C. F. Yang, G. G. Lai, C.-H. Lee, C.-T. Su, G. W. Chang, "Optimal setting of reactive compensation devices with an improved voltage stability index for voltage stability enhancement," International Journal of Electrical Power and Energy Systems, vol. 37, no. 1, pp. 50-57, 2012.

[13] P. Roy, S. Ghoshal, S. Thakur, "Optimal var control for improvements in voltage profiles and for real power loss minimization using biogeography based optimization," International Journal of Electrical Power and Energy Systems, vol. 43, no. 1, pp. 830-838, 2012.

[14] B. Venkatesh, G. Sadasivam and M. A. Khan, "A new optimal reactive power scheduling method for loss minimization and voltage stability margin maximization using successive multi-objective fuzzy LP technique," in IEEE Transactions on Power Systems, vol. 15, no. 2, pp. 844-851, May 2000.

[15] Wei Yan, Shuai Lu and D. C. Yu, "A novel optimal reactive power dispatch method based on an improved hybrid evolutionary programming technique," in IEEE Transactions on Power Systems, vol. 19, no. 2, pp. 913-918, May 2004.

[16] Wei Yan, Fang Liu, C. Y. Chung and K. P. Wong, "A hybrid genetic algorithm-interior point method for optimal reactive power flow," in IEEE Transactions on Power Systems, vol. 21, no. 3, pp. 1163-1169, Aug. 2006.

[17] J. Yu, W. Yan, W. Li, C. Y. Chung and K. P. Wong, "An Unfixed Piecewise-Optimal Reactive Power-Flow Model and its Algorithm for AC-DC Systems," in IEEE Transactions on Power Systems, vol. 23, no. 1, pp. 170-176, Feb. 2008.

[18] F. Capitanescu, "Assessing Reactive Power Reserves With Respect to Operating Constraints and Voltage Stability," in IEEE Transactions on Power Systems, vol. 26, no. 4, pp. 2224-2234, Nov. 2011.

[19] Z. Hu, X. Wang, G. Taylor, "Stochastic optimal reactive power dispatch: Formulation and solution method," International Journal of Electrical Power and Energy Systems, vol. 32, no. 6, pp. 615-621, 2010.

[20] A. Kargarian, M. Raoofat, M. Mohammadi, "Probabilistic reactive power procurement in hybrid electricity markets with uncertain loads," Electric Power Systems Research, vol. 82, no. 1, pp. 68-80, 2012.

[21] X. Meng, Y. Liu, X. Gao, H. Zhang, "A New Bio-inspired Algorithm: Chicken Swarm Optimization," Advances in Swarm Intelligence SE, 8794. 2014, pp. 86-94.

[22] Q. H. Wu and J. T. Ma, "Power system optimal reactive power dispatch using evolutionary programming," in IEEE Transactions on Power Systems, vol. 10, no. 3, pp. 1243-1249, Aug. 1995.

[23] S. Durairaj, D. Devaraj, P. S. Kannan, "Genetic algorithm applications to optimal reactive power dispatch with voltage stability enhancement", Journal of the Institution of Engineers (India): Electrical Engineering Division, vol. 87, pp. 42-47, September 2006.

[24] D. Devaraj, "Improved genetic algorithm for multi-objective reactive power dispatch problem," European Transactions on electrical power, vol. 17, pp. 569-581, 2007.

[25] P. Aruna Jeyanthy, Dr. D. Devaraj, "Optimal Reactive Power Dispatch for Voltage Stability Enhancement Using Real Coded Genetic Algorithm," International Journal of Computer and Electrical Engineering, vol. 2, No. 4, August, 2010 1793-8163.

[26] Wu. Q. H, Y. J. Cao, J. Y. Wen, 1998, "Optimal reactive power dispatch using an adaptive genetic algorithm," International Journal of Electrical Power \& Energy Systems, vol 20, no. 8, pp. 563-569, November 1998.

[27] B. Zhao, C. X. Guo and Y. J. Cao, "A multiagent-based particle swarm optimization approach for optimal reactive power dispatch," in IEEE Transactions on Power Systems, vol. 20, no. 2, pp. 1070-1078, May 2005.

[28] Mahadevan. K, Kannan P. S, 2010, "Comprehensive Learning Particle Swarm Optimization for Reactive Power Dispatch," Applied Soft Computing, vol. 10, no. 2, pp. 641-52, March 2010.

[29] Khazali. A. H, M. Kalantar, "Optimal Reactive Power Dispatch based on Harmony Search Algorithm," Electrical Power and Energy Systems, vol. 33, no. 3, pp. 684-692, 2011.

[30] Sakthivel. S, M. Gayathri, V. Manimozhi, 2013, "A Nature Inspired Optimization Algorithm for Reactive Power Control in a Power System," International Journal of Recent Technology and Engineering, vol. 2, no. 1, pp29-33, March 2013.

[31] Tejaswini Sharma,Laxmi Srivastava,Shishir Dixit, 2016, "Modified Cuckoo Search Algorithm For Optimal Reactive Power Dispatch," Proceedings of 38 th IRF International Conference, Chennai, 2016, pp. 4-8.

[32] C. Dai, W. Chen, Y. Zhu and X. Zhang, "Seeker Optimization Algorithm for Optimal Reactive Power Dispatch," in IEEE Transactions on Power Systems, vol. 24, no. 3, pp. 1218-1231, Aug. 2009.

[33] J. R. Gomes and O. R. Saavedra, "Optimal reactive power dispatch using evolutionary computation: extended algorithms," in IEE Proceedings - Generation, Transmission and Distribution, vol. 146, no. 6, pp. 586-592, Nov. 1999.

[34] IEEE, "The IEEE 30-bus test system and the IEEE 118-test system," (1993), $\mathrm{http}: / /$ www.ee.washington.edu/trsearch/pstca/.

[35] Jiangtao Cao, Fuli Wang, Ping Li, "An Improved Biogeography-based Optimization Algorithm for Optimal Reactive Power Flow," International Journal of Control and Automation, vol. 7, no. 3, pp. 161-176, 2014. 